\title{
Doenças por Prions
}

Abelardo de Queiroz-Campos Araújo*, André Luiz dos Anjos de Oliveira **

\section{RESUMO}

As doenças por prions (proteínas, isentas de ácido nuciéico, com capacidade auto-replicativa) săo um grupo de enfermidades crónicas, progressivas e fatais do sistema nervoso, causadas por agente transmissivel com propriedades físicas, químicas e biológicas nāo convencionais. Essas doenças, ao contrário da maioria das enfermidades existentes, podem ser esporádicas, transmissiveis ou genéticas. As principals doenças humanas causadas por prlons sảo o Kuru, a doença de Creutzfeldt-Jakob e suas varlantes, a doença de GerstmannStrăussler-Scheinker $\theta$ a insônia familiar fatal. Neste artigo revêm-se os principais - $\theta$ mais recentes - aspectos etiopatogênicos, anátomo. patológicos, clínicos e terapêuticos acerca deste importante grupo de enfermidades neurodegenerativas.

\section{UNITERMOS}

Encefalopatias espongiformes, doença de Creutzfeldt-Jakob, prions, amiloidoses, deméncias.

\footnotetext{
- Professor Adjunto de Neurologia - UfRJ; Neurovirologista do Hospltal Evandro Chagas - Fiocruz;

** Bolsista PIBIC/CNPq do Instituto Oswaldo Cruz - Fiocruz
}

\section{INTRODUÇÃO}

Por mais de dois séculos, criadores de ovelhas europeus já conheciam a existência de um mal endêmico que afetava os seus rebanhos e que se disseminava de maneira peculiar. A doença só acometia um rebanho saudável quando um animal oriundo de um rebanho doente era agregado aos animais sãos. As ovelhas acometidas sofriam de uma enfermidade progressiva, e invariavelmente fatal, caracterizada por incoordenação motora, tremor, emagrecimento e, frequientemente, intenso prurido que fazia com que os animais se roçassem furiosamente de encontro às cercas. Por esta razão, a doença era conhecida na Inglaterra, Austrália e Nova Zelândia pela alcunha de scrapie. Em outros países a enfermidade era, e ainda é, conhecida por designações diversas, tais como tremblant na França, rida na Islândia, Traberkrankheit na Alemanha e klusavka na Eslováquia ${ }^{70}$. Em 1936 Crullé e Chelle conseguiram, pela primeira vez, transmitir experimentalmente a doença a ovelhas, demonstrando a sua natureza infecciosa e provando ter 0 agente causal propriedades virais ${ }^{24}$. Inaugurava-se, portanto, uma era de intensas investigações que levariam à caracterização de um grupo de enfermidades do sistema nervoso ( $\mathrm{SN}$ ) atualmente conhecidas por diversas designações, sendo doenças por prions a mais utilizada.

A primeira enfermidade humana deste grupo, a doença de CreutzfeldtJakob (DCJ), foi descrita, independentemente, na década de 20, pelo neuropsiquiatra Hans-Gerhardt Creutzfeldt, enquanto trabalhava com Spielmeyer, em Munique ${ }^{23}$, e por Alfons Maria Jakob, neuropatologista de Hamburgo $^{46}$. Embora o trabalho de Creutzfeldt anteceda o de Jakob em nove meses, alguns autores mais modernos colocam em dúvida o seu diagnóstico, feito em uma mulher de 23 anos, com dois irmãos com retardo mental e apresentando tiques, mioclonias, crises convulsivas focais e síndrome piramidal. Os três casos descritos por Jakob, por outro lado, parecem se adequar mais ao diagnóstico, razão pela qual alguns acham mais justa a designação de doença de Jakob-Creutzfeldt.

Cerca de 30 anos depois dos relatos originais de Creutzfeldt e Jakob, em meados da década de 50, Carleton Gajdusek e seus assistentes foram enviados para o interior de Papua-Nova Guiné para estudar uma misteriosa doença 
que acometia nativos do grupo lingüístico-cultural Fore, residentes em algumas vilas situadas no planalto central daquele arquipélago. A enfermidade, conhecida localmente pelo nome $K u r u$, afetava principalmente mulheres e crianças, permanecendo como um mistério etiológico por vários anos. Em 1959, Hadlow, um veterinário escocês, em carta à revista inglesa The Lancet, chamou a atenção para as similaridades anatomopatológicas entre o Kuru e o scrapie. Isso levou Gajdusek e seu grupo a intensa busca de um nexo comum entre as duas doenças, inoculando material obtido de cérebro de doentes com Kuru em chimpanzés. Em 1965, finalmente, após um ano e meio de inoculados, chimpanzés infectados intracerebralmente desenvolveram doença clínica e anatomopatológica similar ao Kuru. Provava-se assim, pela primeira vez, a natureza transmissível do Kuru ${ }^{30}$. Essa descoberta levou Gajdusek a ganhar o prêmio Nobel alguns anos depois. Muitas dúvidas, entretanto, ainda permaneciam acerca da natureza do agente etiológico envolvido no processo. Quase 15 anos depois, Stanley Prusiner e colaboradores postularam que o agente etiológico envolvido nessas doenças seria uma proteína, isenta de ácido nucléico, com capacidade auto-replicativa, a qual denominaram prion (proteinaceous infectious particle) ${ }^{63}$.

Apesar de todos os avanços obtidos no conhecimento destas doenças, muitos fatos ainda permanecem obscuros, inclusive no que tange à uniformização da designação desse grupo de enfermidades. A presente revisão objetiva, em última análise, atualizar o profissional não especializado acerca dos principais aspectos clínicos e etiopatogênicos envolvidos nessas doenças.

\section{DEFINIÇÃO}

As doenças por prions são um grupo de enfermidades crônicas, progressivas e fatais do sistema nervoso, causadas por agente transmissível com propriedades físicas, químicas e biológicas não convencionais. Essas doenças, ao contrário da maioria das enfermidades existentes, podem ser esporádicas, transmissíveis ou genéticas. Ainda não existe um consenso acerca da melhor designação para essas enfermidades. Apesar de o termo "doenças por prions" ser cada vez mais utilizado na literatura, outras designações ainda podem ser encontradas, tais como: doenças por vírus lentos, demências virais transmissíveis, amiloidoses virais transmissíveis e encefalopatias espongiformes subagudas ou transmissíveis ${ }^{29}$.

\section{CLASSIFICAÇÃO}

A Tabela 1 mostra as principais doenças por prions conhecidas e as principais mutações envolvidas nas suas formas genéticas.

\section{ETIOPATOGENIA}

As doenças por prions (DP) são causadas por agente etiológico com características bastante incomuns. O seu agente causador ainda não foi definitivamente estabelecido e a sua definição e caracterização têm suscitado grandes discussões na literatura especializada.

$O$ pequeno tamanho (pois são agentes filtráveis) e a natureza transmissível sugeriam, a princípio, tratar-se de agente viral; no entanto, sua extrema resistência à inativação por raios $\mathrm{X}$ ou ultravioleta, ou mesmo por agentes químicos, como detergentes, ou bioquímicos, como nucleases, proteases e glicosidases, levaram Griffith, ainda em 1967, a postular que este agente poderia consistir de proteína com capacidade replicativa própria, sem estar associada a um ácido nucléico ${ }^{41}$.

As primeiras tentativas de se purificar o agente das DP por meios biofísicos levaram à identificação, em 1982, de uma proteína protease-resistente, denominada PrP (Protease-resistant Protein ou Prion) ${ }^{6}$. Estudos subsequientes de sequienciamento e clonagem revelaram que a PrP é uma proteína celular normal, de 33 a $35 \mathrm{kD}$, codificada por um gene situado no cromossoma 20 , expressa em diversas células e tecidos não infectados. Após a infecção, a PrP normal $\left(\operatorname{PrP} \mathrm{P}^{\mathrm{C}}\right)$ é convertida numa forma macromolecular anormal, proteinase-resistente $\left(\mathrm{PrP}^{\mathrm{Sc}}\right)^{60}$. Esta forma anormal de $\operatorname{PrP}$ acumula-se então no cérebro, ou sob a forma de depósitos difusos ou em placas amilóides. Deste modo, de acordo com a teoria proposta por Prusiner, a $\operatorname{PrP}^{\mathrm{Sc}}$ seria um componente essencial da partícula priônica infecciosa, ou, ainda, a $\mathrm{PrP}^{\mathrm{Sc}}$ seria o próprio agente etiológico destas doenças ${ }^{64}$. $\mathrm{Na}$ Tabela 2 encontram-se resumidas algumas propriedades das formas normais e anormais das PrP.

A evidência mais forte a favor do papel das PrP na patogenia das DP é a demonstração de que camundongos sem um gene PrP funcionante são imunes à infecção por scrapie $^{14}$. Apesar disso, ainda não se conhece exatamente o real papel patogênico das PrP. As duas hipóteses mais aceitas a esse respeito são:

- as PrP poderiam ser o próprio agente infeccioso;

- as PrP poderiam desempenhar papel crucial em alguma etapa do processo patogênico, a saber:

- as PrP poderiam atuar como receptor - ou co-fator - para o agente transmissível; 
- as PrP poderiam ser mediadoras do dano tecidual causado por um agente infeccioso convencional mas de alta resistência à inativação.

Os genes codificadores da $\operatorname{PrP}$ estão situados no braço curto do cromossoma 20 humano e em região homóloga do cromossoma 2 do rato. Isto sugere a existência desses genes antes mesmo da separação dos mamíferos ${ }^{67}$. A estrutura e organização dos genes $\operatorname{Pr} P$ são demonstradas na Figura 1.

Embora o RNA mensageiro (RNAm) do gene PrP seja expresso constitutivamente no cérebro de animais adultos, ele parece sofrer uma elevada taxa de regulação durante o desenvolvimento. Assim, seus níveis parecem aumentar em paralelo à maturação do $\mathrm{SN}^{58}$. Estudos com técnicas de hibridização in situ demonstram que os mais altos níveis de RNAm de PrP são encontrados em neurônios 52 .

Uma vez que não existem anticorpos monoclonais que distingam a $\operatorname{PrP}^{\mathrm{C}}$ da $\operatorname{PrP}^{\mathrm{Sc}}$, os níveis teciduais de $\mathrm{PrP}^{\mathrm{C}}$ costumam ser medidos em tecidos de animais sabidamente não carreadores de $\operatorname{PrP}^{\mathrm{Sc}}$. Por outro lado, a $\operatorname{PrP}^{\mathrm{Sc}}$ é quantificada em tecidos de animais infectados, mas somente após o material ter sido submetido a tratamento com enzimas proteolíticas que hidrolisem a $\operatorname{PrP}^{\mathrm{C}}$. Através de técnicas de imunoistoquímica e histoblotting é possível se estudar a expressão tecidual da $\operatorname{PrP}^{C}$. Assim, os diversos estudos a esse respeito têm levado à impressão de que os prions sejam transportados ao longo dos axônios, por fluxo axonal retrógrado ${ }^{47}$.

Uma diferença fundamental entre as formas normal e patológica de PrP é a sua velocidade de síntese e degradação. Em culturas de células, a $\operatorname{PrP}^{\mathrm{C}}$ é rapidamente sintetizada e degradada. A $\operatorname{Pr} \mathrm{P}^{\mathrm{Sc}}$, ao contrário, é sintetizada lentamente, através de processo póstradução ${ }^{8}$.

A PrP ${ }^{\mathrm{C}}$ transita pelo aparelho de Golgi sendo, presumivelmente, transportada no interior de vesículas secretórias para a superfície da célula, onde se liga à membrana celular por meio de âncora fosfolipídica de glicoinositol. Aparentemente a $\operatorname{Pr} \mathrm{P}^{\mathrm{C}}$ retorna ao interior da célula pelos cavéolos, sendo então degradada, em cerca de seis horas, no compartimento endossomal ${ }^{8}$.

Apesar do grande acúmulo de conhecimentos nos últimos anos, a real função da $\operatorname{PrP}^{\mathrm{C}}$ ainda é um mistério. Acredita-se que ela possa funcionar ou como receptor de superfície celular ou como molécula de adesão, ou ainda como fator trófico ${ }^{69}$. Por outro lado a $\operatorname{PrP}^{\mathrm{C}}$ não parece ser uma proteína essencial, ao menos em camundongos transgênicos PRNP ${ }^{0 / 0}$. Esses animais, desprovidos do gene PrP por engenharia genética, desenvolvem-se perfeitamente, sem que se evidencie qualquer anomalia no sistema nervoso, músculo-

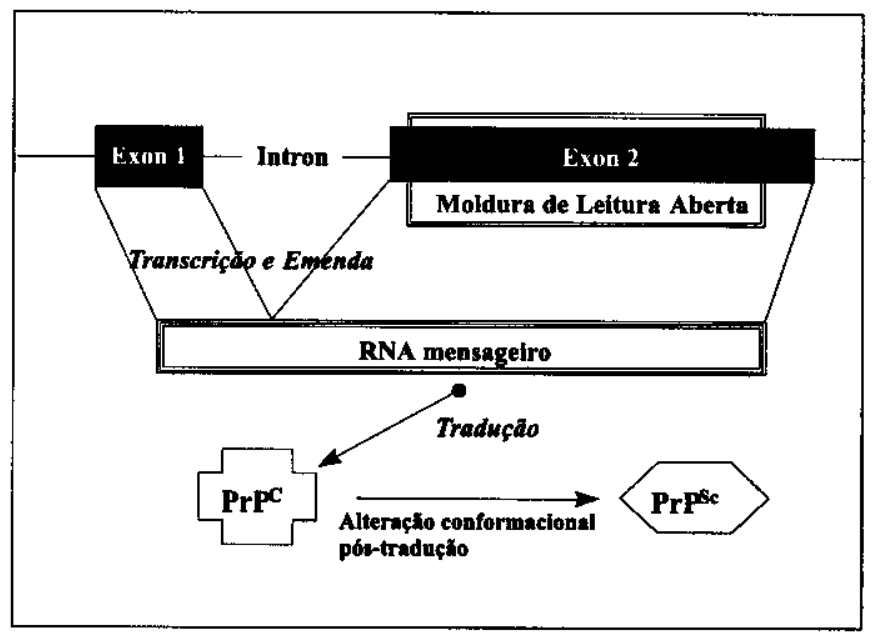

Fonte: Chesebro, B; Fields, BN. Transmissible spongiform encephalopathies: a brief introduction. In: Fields Virology. Fields, BN; Knipe, DM; Howley, PM; et al. (eds). Lippincott-Raven: Philadelphia, 1996, p. 2845-2849.

\section{FIGURA 1}

Estrutura e organização do gene $\operatorname{PrP}$

esquelético ou linforreticular ${ }^{15}$. Este achado pode indicar que as doenças por prions não resultem de uma inibição da função da $\operatorname{PrP}^{\mathrm{C}}$ pela $\operatorname{PrP}^{\mathrm{Sc}}$, mas sim do acúmulo de $\operatorname{PrP}^{\mathrm{Sc}}$, que interferiria em algum processo celular ainda não definido.

Estudos eletrofisiológicos em cortes histológicos de hipocampo de camundongos $\mathrm{PRNP}^{0 / 0}$ sugerem que a ausência de $\operatorname{PrP}^{\mathrm{C}}$ altera a formação de sinapses ${ }^{22}$. Outros estudos mostram que a $\operatorname{PrP}^{\mathrm{C}}$ é transportada ao longo dos axônios tanto no sistema nervoso central (SNC) quanto no periférico ${ }^{7}$. Finalmente foi demonstrado, por imunocitoquímica, que a $\operatorname{PrP}^{C}$ é encontrada na junção neuromuscular'. As implicações do conjunto destes dados ainda não estão muito claras no sentido de esclarecer o real papel fisiológico da $\operatorname{PrP}^{\mathrm{C}}$.

Diversos experimentos têm demonstrado que as moléculas de $\mathrm{PrP}^{\mathrm{C}}$ ganham a superfície celular antes do evento que as transformarão em $\operatorname{PrP}^{\mathrm{Sc}}$. Após atingirem a superfície, as $\operatorname{PrP}^{\mathrm{C}}$ tornam a penetrar na célula, localizando-se ou no interior de cavéolos ou de endossomos. Aí então, dentro desses compartimentos subcelulares, as $\operatorname{PrP}^{\mathrm{C}}$ ou sofrem o processo de degradação normal, ou são convertidas em $\operatorname{PrP}^{\mathrm{Sc}}$. Ao contrário das $\operatorname{PrP}^{\mathrm{C}}$, as $\mathrm{PrP}^{\mathrm{Sc}}$ acumulam-se primariamente no interior das células, depositando-se em vesículas citoplasmáticas que aparentam ser lisossomos secundários $9,69,71$. 
A sequiência de aminoácidos da $\mathrm{PrP}^{\mathrm{Sc}}$ é idêntica à da $\operatorname{PrP}^{\mathrm{C} 68}$. Este fato sugere que diferenças na conformação estrutural distingam as duas isoformas de PrP. Determinações da estrutura secundária das PrP revelaram que a $\operatorname{PrP}^{\mathrm{C}}$ tem um elevado conteúdo de alfa hélices ( $42 \%$ ) e pouquíssimas lâminas beta ( $3 \%)$. Em contraste, a $\mathrm{PrP}^{\mathrm{Sc}}$ contém $43 \%$ de lâminas beta e $30 \%$ de alfa hélices ${ }^{61}$. Portanto, a diferença básica entre ambas as isoformas de $\operatorname{PrP}$ está na sua estrutura protéica secundária. Assim, alterações conformacionais que ocasionam mudança de uma estrutura pobre em lâminas beta $\left(\operatorname{Pr} P^{C}\right)$ numa estrutura rica nessas estruturas $\left(\mathrm{PrP}^{\mathrm{Sc}}\right)$ constituem o substrato básico à conversão da-isoforma normal na patológica. Uma vez que a $\operatorname{Pr} P^{\mathrm{Sc}}$ parece ser o único componente da partícula infecciosa priônica, é provável que esta transição conformacional constitua-se num evento fundamental à propagação dos prions. Aparentemente, a resistência à proté́lise, bem como as propriedades amiloidogênicas da $\operatorname{Pr}^{\mathrm{Sc}}$ devem-se à sua alta hidrofobicidade. Segundo hipótese - ainda não comprovada - do grupo de Prusiner, a conversão final $\operatorname{PrP}^{\mathrm{C}}$ à $\operatorname{PrP}^{\mathrm{Sc}}$ seria antecedida da formação de uma estrutura intermediária denominada PrP*.

$\mathrm{Na}$ realidade, não se sabem exatamente os reais mecanismos de formação e propagação das partículas priônicas infectantes. As teorias mais recentes sugerem, no entanto, algumas possibilidades. A multiplicação anômala dos prions é um processo exponencial no qual a conversão pós-tradução de $\operatorname{PrP}^{\mathrm{C}}$ em $\operatorname{PrP}^{\mathrm{Sc}}$, ou num possível precursor ( $\left.\mathrm{PrP}^{*}\right)$, parece ser mandatória. Flutuações estocásticas (i.e., ao acaso) na estrutura da $\operatorname{PrP}^{\mathrm{C}}$ podem levar à criação de uma estrutura monomérica rara, parcialmente desdobrada do ponto de vista tridimensional. Esta estrutura, denominada $\operatorname{PrP} *$, por sua vez, pode se converter novamente em $\operatorname{PrP}^{\mathrm{C}}$, ou, ainda, ser degradada antes da sua conversão final em $\operatorname{PrP}^{\text {Sc }}$. A infecção com prions exógenos contendo $\operatorname{PrP}^{\mathrm{Sc}}$ agiria como molde na conversão de $\mathrm{PrP}^{*}$ em $\mathrm{PrP}^{\mathrm{Sc}}$. A insolubilidade do $\operatorname{Pr} \mathrm{P}^{\mathrm{Sc}}$ tornaria esse processo irreversível, levando à formação de $\operatorname{Pr} P^{*}$ e de $\operatorname{PrP}^{\text {sc }}$ por uma reação em cadeia. A deposição da proteína anormal $\left(\operatorname{PrP}^{\mathrm{Sc}}\right)$ no $\mathrm{SNC}$ levará às alterações histopatológicas encontradas nas DP.

A PrP ${ }^{S c}$ combina-se à $\operatorname{Pr} P^{*}$ ou $\operatorname{PrP}^{C}$ para formar um complexo molecular de vida transitória que será, subsequientemente, transformado em duas moléculas de $\operatorname{PrP}^{\mathrm{Sc}}$. Num próximo ciclo, essas duas novas moléculas de $\operatorname{PrP}^{\mathrm{Sc}}$ combinar-se-ão a duas moléculas de PrP* ou $\operatorname{Pr} \mathrm{P}^{\mathrm{C}}$ dando origem a dois complexos moleculares que, por sua vez, se dissociarão para se combinar com quatro moléculas de $\operatorname{PrP} *$ ou $\operatorname{PrP}^{\mathrm{C}}$, criando assim um processo exponencial ${ }^{19}$. Tentativas de se produzir novas proteínas $\mathrm{PrP}^{\mathrm{Sc}}$ a partir da mistura de $\mathrm{PrP}^{\mathrm{Sc}}$ com $\operatorname{PrP}^{\mathrm{C}}$ foram infrutíferas. Isso levanta a possibilidade da existềncia de outra proteína, espécie-específica e não codificada pelo gene PrP (caperonas, por exemplo), envolvida no processo de catálise das alterações conformacionais que atuam na formação da $\mathrm{PrP}^{\mathrm{Sc}}$. Esta proteína catalisadora, ainda não identificada, foi denominada de proteína $\mathrm{Y}^{64}$.

Doenças priônicas esporádicas podem resultar do acúmulo, relativamente infreqüente, de uma quantidade suficiente de $\operatorname{PrP}^{*}$ para produzir $\operatorname{PrP}^{S c}$. De forma alternativa, mutações somáticas podem desestabilizar a $\operatorname{Pr} \mathrm{P}^{\mathrm{C}}$, promovendo a sua conversão a $\operatorname{Pr} \mathrm{P}^{* 64}$.

A passagem de prions entre espécies diferentes é um processo estocástico caracterizado por prolongados períodos de incubação. Prions sintetizados de novo refletem a sequiência do gene $\operatorname{PrP}$ do hospedeiro e não aquela das moléculas do inóculo. Numa passagem subsequiente em hospedeiro homólogo o período de incubação se encurta, tornando-se um processo nãoestocástico. Este conceito de barreira entre espécies tem implicações práticas, principalmente na avaliação do risco de desenvolvimento de DCJ por indivíduos que consumiram carne de cordeiro infectada por scrapie ou carne de vacas com encefalopatia espongiforme bovina (EEB). Diferenças na seqüência do gene PrP podem ser responsáveis pela existência desta barreira. Assim, aparentemente, a síntese de novo dos prions parece ser espécie-específica, refletindo a origem genética dos prions inoculados ${ }^{11}$.

Mutações no gene PrP pode dar origem a DP hereditárias. Tem-se demonstrado, inclusive em várias espécies animais, que variações alélicas e mutações nos genes PrP podem influenciar o fenótipo das DP. Em seres humanos, algumas mutações agem como genes autossômicos dominantes, causando, por exemplo, a doença de Gerstmann-Sträussler-Scheinker (GSS) e DCJ familiar. $O$ gene PrP mutante pode também ser "ativado" a uma forma transmissível por vários estímulos externos.

Ainda é incerto o exato papel da substância amilóide na patogenia das DP. Placas amilóides e fibrilas nem sempre são encontradas na secções cerebrais de indivíduos acometidos. Apesar disso, nestes mesmos espécimes, sempre se encontram prions, o que faz supor que nem sempre a presença de prions leve à formação de substância amilóide in vivo ${ }^{64}$.

Recentemente, conseguiu-se gerar prions em um sistema experimental acelular in vitro ${ }^{51}$. Desta forma, aparentemente os prions podem, à semelhança com outras proteínas amilóides, propagar-se por meio de interações com proteínas precursoras - ou peptídeos em processo análogo à cristalização. Apesar disso, até o presente momento, este sistema acelular experimental 


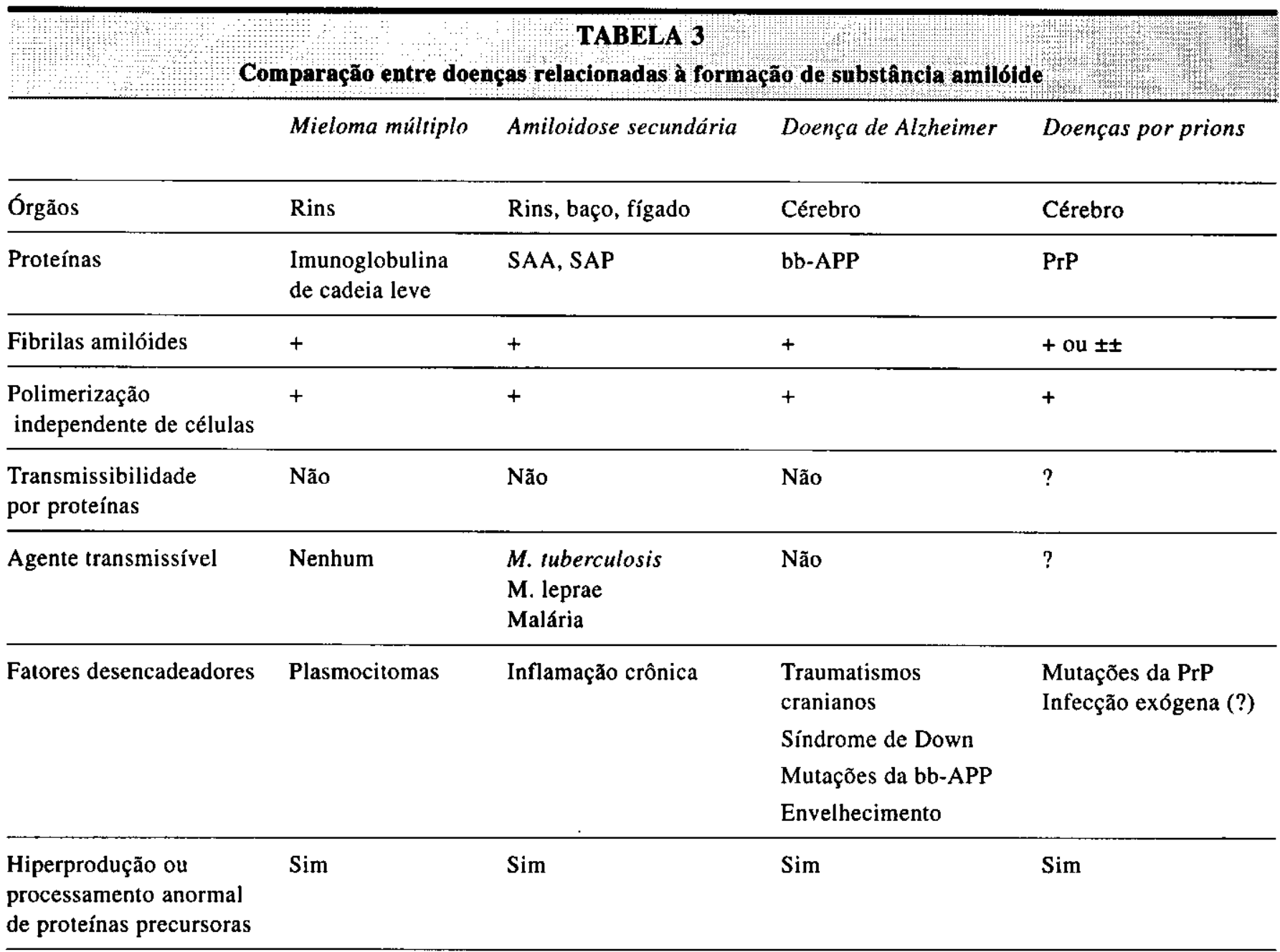

Fonte: adaptado de Chesebro, B; Fields, BN. Transmissible spongiform encephalopathies: a brief introduction. In: Fields Virology. Fields, BN; Knipe, DM; Howley, PM; et al. (eds). Lippincott-Raven: Philadelphia, 1996, p. 2845-2849.

não foi capaz de fornecer evidências suficientemente fortes que afastem a possibilidade do envolvimento de um agente infeccioso adicional. Desta forma, no estágio atual dos conhecimentos, pode ser interessante a comparação entre as DP e outras enfermidades patologicamente relacionadas à formação de substância amilóide (Tabela 3). Esta comparação leva a várias conjecturas $^{17}$, a saber:

- as DP podem ser transmitidas por um agente convencional (em analogia às micobacterioses ou à malária);

- as DP podem ser creditadas à superprodução - ou processamento anormal - de proteína precursora signs do hospedeiro de modo a gerar uma forma protéica metabolicamente estável e resistente ao catabolismo normal in vivo. Isto poderia ser induzido por fatores genéticos, como mutações no próprio gene da proteína precursora, ou, ainda, por fatores exógenos.

\section{NEUROPATOLOGIA}

As alterações histopatológicas das DP estão restritas ao SNC, evidenciando-se patognomonicamente por uma encefalopatia espongiforme subaguda ${ }^{57}$. A degeneração causada pelo processo patológico é tão rápida que, macroscopicamente, há apenas um leve grau de atrofia cortical, quando esta encontra-se presente.

As principais lesões neurocitológicas das DP são: 
- defeito progressivo na formação da membrana plasmática, com vacuolização do corpo neuronal, axônios e dendritos e, em menor monta, dos astrócitos e oligodendrócitos;

- extensa hipertrofia e proliferação astroglial e, em menor escala, microglial;

- status spongiosus da substância cinzenta, principalmente no cerebelo, com maciça depleção neuronal;

- ausência de infiltrado inflamatório;

- depósitos de placas amilóides de $\operatorname{PrP}^{\mathrm{Sc}}$, nos córtex cerebelar e cerebral.

Existem, entretanto, acentuadas diferenças anatomopatológicas entre as diversas formas de apresentação clínica das DP. No Kuru encontra-se "cuff" perivascular que, como as outras alterações, são mais proeminentes no cerebelo. As placas de Kuru, formadas por depósitos amilóides, são identificadas nos córtex cerebral e cerebelar ${ }^{31,50}$. Na DCJ, a degeneração espongiforme está disseminada, principalmente no córtex cerebral, corpo estriado, tálamo e cerebelo. Apenas 5\% dos casos possuem placas amiloides como as verificadas no Kuru. Métodos imunoistoquímicos podem diferenciar os depósitos amiloides encontrados na DCJ e GSS das placas senis presentes em outras enfermidades ${ }^{49}$. A confirmação definitiva da presença de depósitos de $\operatorname{PrP}^{\mathrm{Sc}}$ pode ser estabelecida através de métodos como o Western-blot, em material extraído de tecido neural ${ }^{5}$. Na doença de GSS, as principais alterações neuropatológicas consistem em encefalopatia espongiforme e perda neuronal e de mielina, além de emaranhados neurofibrilares. Um grande número de placas amiloides pode ser identificado no córtex cerebral e cerebelar, tálamo e algumas vezes no tronco encefálico ${ }^{56}$. A insônia familiar fatal (IFF), por sua vez, apresenta atrofia talâmica, sendo as alteraçōes espongiformes encontradas apenas em indivíduos com doença de longa duração ${ }^{34}$.

\section{CLINICA E DIAGNÓSTICO}

\section{Kuru}

Kuru, em dialeto Fore, significa "tiritar, tremer" e designa a mais estereotipada das DP. Caracteriza-se por tremores "tiritantes" e ataxia cerebelar progressivos, deflagrando o b́bito do paciente em período inferior a um ano. Foi descrita por Gajdusek e Zigas, em 1957 na região do planalto da Nova Guiné, onde
$80 \%$ dos casos ocorriam entre as pessoas do grupo lingüístico Fore ${ }^{31,27}$. Sua similaridade com o scrapie, observada por Hadlow em $1959^{42}$, levou à sua inclusão na lista de doenças causadas por agentes nãoconvencionais em 1966.

$\mathrm{Na}$ época de sua descrição, atingia $1 \%$ da populaçāo na região endêmica, representando a doença mais prevalente e a principal causa mortis entre o grupo Fore. Acometia praticamente todas as faixas etárias acima dos 5 anos, sendo freqüente em crianças de ambos os sexos e mulheres adultas, e rara em homens adultos. A razão entre mulheres e homens era de 2:1 para todo o grupo, chegando a $3: 1 \mathrm{em}$ determinadas aldeias ${ }^{28}$. Glasse, aliando essas duas informações, concluiu, em 1967, que o Kuru seria transmitido através do canibalismo ritual praticado por este povo, principalmente por mulheres e crianças ${ }^{38}$. A infecção se dava através do contato da pele e mucosas com tecido neural altamente infeccioso, que chega a ter $10^{8}$ doses infecciosas por grama ${ }^{28}$. Estimase que $90 \%$ das crianças expostas ao agente desenvolveram a doença. Uma vez que nenhum indivíduo alheio aos grupos endêmicos adquiria Kuru, eliminouse a possibilidade de outras formas de transmissão, como ciclos biológicos não-humanos ${ }^{29}$.

$A$ incidência da enfermidade diminuiu significativamente nos últimos anos. Em 1975, já não havia mais pacientes com idade inferior a 20 anos; em 1985 , o paciente mais novo tinha 35 anos. Atualmente nenhum caso novo é constatado na região. A partir do abandono dos rituais de canibalismo há mais de $\mathbf{3 0}$ anos, graças à iniciativa do governo em desencorajar tal prática, nenhuma criança nascida desde então desenvolveu Kuru. Isto contraria a hipótese de transmissão vertical da doença e evidencia um período de incubação do Kuru de 30 anos ou mais ${ }^{29}$.

O quadro clínico predominante no Kuru era de ataxia cerebelar insidiosa, que progredia até incapacitação total e morte, geralmente dentro de três a nove meses. Os primeiros sintomas consistiam em instabilidade subjetiva da marcha, instabilidade postural e ataxia distal dos membros superiores e dos olhos, além de disartria. Alguns pacientes apresentavam pródromo de cefaléia e dor nos membros. Durante todo o curso clínico, o paciente permanecia afebril - exceto por ocasião de intercorrências secundárias - e sem sinais de demência e de alterações sensitivas. Os tremores eram desordenados inicialmente, remetendo aos de leve grau de hipersensibilidade ao frio. A inabilidade de manter-se equilibrado em um só pé servia precocemente de importante pista para o diagnóstico.

Num segundo estágio, os pacientes mostravam-se incapazes de deambular sem apoio, exibindo também 
bradipsiquismo. Notava-se agravamento progressivo da ataxia e da disartria. Os doentes passavam a apresentar rigidez associada a mioclonias, movimentos coreoatetóides, estes últimos especialmente em resposta à instabilidade postural exagerada, ou exposição súbita ao barulho ou à luz. Ao exame clínico, verificava-se a existência de clônus patelar e aquileu e preservação dos reflexos profundos; sinal de Babinski, miofasciculações ou fraqueza e atrofia muscular estavam ausentes.

Em estágio terminal, a ataxia, os tremores e a disartria tornavam-se incapacitantes. Os reflexos tendíneos exacerbavam-se, e o paciente apresentava flacidez generalizada, sinais de comprometimento bulbar, incontinência urinária e fecal, e disfagia de tal modo grave que era incapaz de ingerir sólidos ou líquidos. A incapacidade física acarretava o aparecimento de úlceras de decúbito e pneumonia hipostática, os pacientes tornando-se mudos e irresponsivos. Finalmente os doentes sucumbiam, tão rapidamente que ainda mantinham algum grau de lucidez.

A importância do Kuru nos dias de hoje é meramente histórica, por ter sido a primeira DP descrita em humanos, o que levou à abertura de vasto campo de conhecimentos acerca dessas enfermidades.

\section{Doença de Creutzfeldt-Jakob}

A Doença de Creutzfeldt-Jakob (DCJ) é a mais frequiente das DP, com prevalência aproximada de 1 caso por milhão de habitantes. Sua forma esporádica responde por $90 \%-95 \%$ de todas as $\mathrm{DP}^{29}$. Constitui-se de uma enfermidade degenerativa rara, caracterizada por demência de progressão rápida, mioclonias e achados eletroencefalográficos e neuropatológicos característicos.

A doença tem um pico de incidência em torno dos 60 anos, mas a instalação pode ocorrer desde a puberdade até a oitava década de vida. Precedendo a instalação insidiosa da doença, o paciente apresenta sintomatologia psiquiátrica e comportamental, tais como dismnésia, perda da capacidade de concentração, agitação ou depressão, concomitantemente a disfunção vestíbulo-cerebelar - marcha atáxica, vertigens e nistagmo. Em 1/3 dos pacientes, verifica-se pródromo de alterações nos padrões de sono e alimentares. Eventualmente o quadro clínico pode manifestar-se de forma mais rápida, com confusão mental, vertigens, diplopia e cefaléia ${ }^{10}$. Dentro de poucas semanas a meses, torna-se evidente o quadro demencial, e ocorre rápida evolução da ataxia cerebelar, somando-se a esta mioclonias, tremores, coreoatetose e piramidalismo. Freqüentemente, podem-se verificar distúrbios visuais, disfagia e sinais parkinsonianos caracterizados particularmente por rigidez generalizada. Num estágio terminal, o paciente encontra-se francamente torporoso, com sinais de decorticação e descerebração. Surgem respostas mioclônicas maciças a diversos estímulos sensoriais, dando uma falsa impressão de que o paciente está alerta e responsivo. A doença é fatal dentro de um ano em mais de $90 \%$ dos casos, com grande parte destes falecendo em no máximo cinco meses após a instalação da doença. Apenas $9 \%$ dos pacientes sobrevivem por dois ou mais anos. A Tabela 4 sumariza alguns critérios propostos para o diagnóstico da DCJ.

Além da forma clássica, relatada anteriormente, descrevem-se outras formas de DCJ, a saber: formas predominantemente cerebelares; formas predominantemente mioclônicas; formas amiotróficas; formas com quadro predominante de cegueira cortical (forma de Heidenhain); formas de evolução arrastada (superior a dois anos), correspondendo a cerca de $5 \%$ dos casos. Em todas essas variantes, aos achados descritos somase o quadro demencial ${ }^{10,29}$.

Anormalidades eletroencefalográficas estão presentes em $75 \%$ dos casos, com ritmo de fundo lento e difuso e sobreposição de complexos bifásicos ou trifásicos periódicos, unilaterais ou difusos, na freqüência de $1 \mathrm{~Hz}$, geralmente em associação com a atividade mioclônica. $O$ traçado varia com as fases da doença ${ }^{2.18}$. Durante todo o curso clínico da DCJ esporádica, o paciente encontra-se afebril, e o hemograma não apresenta maiores alterações. $O$ exame do líquido cefalorraquiano (LCR) costuma ser normal, exceto por leve a moderada hiperproteinorraquia em alguns casos. Mais recentemente, foi desenvolvido um radioimunoensaio simples e rápido capaz de identificar uma fração protéica liquórica anormal denominada 143-3. Esta tem-se revelado um marcador altamente sensível e específico para DP em humanos e animais, embora alguns pacientes com encefalites e com acidentes vasculares encefálicos recentes possam apresentar resultados falsamente positivos ${ }^{45}$.

A forma iatrogênica, ou transmissível, de DCJ possui duas rotas de infecção entre humanos. Uma delas é através de inoculação direta da $\operatorname{PrP}^{\mathrm{Se}}$ no SNC, como em receptores de transplante de cornea ${ }^{25}$, em pacientes craniotomizados para neurocirurgia ou submetidos a implante de eletrodos ${ }^{4}$, e em pacientes que recebiam implantes de dura-máter ${ }^{72}$. Outra forma possível de transmissão é pelo contato mucocutâneo com tecido 


\section{TABELA 4}

\section{Critérios dlagnósticos para a Doença de Creutrfeldt-Jakob}

Doença de Creutzfeldt-Jakob

Definitiva

indivíduo

\section{Critérios}

Encefalopatia espongiforme confirmada anatomopatologicamente em

com demência progressiva e, pelo menos, um dos seguintes achados:

- mioclonias;

- sinais piramidais;

- sinais cerebelares;

- sinais extrapiramidais;

Provável

Os acima mas sem comprovação anatomopatológica.

Possível

História de demência progressiva com:

- mioclonias e curso inferior a 3 anos;

- familiar com doença de DCJ definitiva ou provável;

- ao menos 2 das características definitivas + sinais precoces e proeminentes de lesão do segundo neurônio motor (forma amiotrófica)

Achados anatomopatológicos característicos

Fonte: adaptado de Masters, CL; Harris, JO; Gajdusek, DC, et al. Creutzfeldt-Jakob disease: patterns of worldwide occurrence and the significance of familial and sporadic clustering. Ann Neurol, 5: 177-188, 1979.

neural infectado, como hormônio do crescimento, gonadotrofina hipofisária e por exposição ocupacional de neurocirurgiões ou técnicos de laboratório ${ }^{13}$. É importante ressaltar que o convívio e o contato com os pacientes portadores de DCJ não predispõem ao desenvolvimento da doença.

Nesta forma iatrogênica a via de inoculação determina o padrão de acometimento clínico. Quando a exposição é direta, o paciente desenvolve uma doença idêntica à DCJ esporádica. Um padrão similar ao Kuru se manifestará caso a via de inoculação seja periférica. Isto sustenta a hipótese de que o Kuru teve início com um caso de DCJ esporádico, em um nativo da região Fore $^{44}$.

Um padrão familiar, com herança autossômica dominante é encontrado em apenas $5 \%$ dos casos de DCJ. Conforme dito anteriormente, diferentes mutações causam expressões fenotípicas diversas ${ }^{12,39}$. A forma clínica mais comum deve-se à mutação no códon 200 , e está presente em famílias judias nascidas na Líbia ${ }^{16}$, na zona rural da Eslováquia ${ }^{40}$ e do Chile ${ }^{11}$. Tem instalação ligeiramente mais precoce, entre a terceira e a quinta décadas de vida, e duração mais prolongada. Manifesta-se de maneira bem semelhante à DCJ clássica, porém pode haver paralisia supranuclear e neuropatia periférica desmielinizante em alguns casos, embora, usualmente, as DP estejam restritas ao SNC. A patogenia deste fenômeno é ainda obscura, não sendo possível demonstrar a expressão da $\operatorname{Pr} P^{S c}$ nos nervos periféricos.

A mutação no códon 178 foi primeiramente encontrada numa família finlandesa ${ }^{43}$, sendo achada posteriormente em outras famílias norte-americanas de ascendências européia e chinesa ${ }^{12,59}$. Sua expressão fenotípica depende, conforme exposto anteriormente, de polimorfismo no códon 129 , determinando IFF ou uma forma de DCJ iniciada em torno dos 46 anos, e de longa duração (23 meses, em média).

Quando a mutação no gene que codifica a $\operatorname{Pr} P$ encontra-se alocada no códon 210 , como foi encontrada 
em uma família francesa ${ }^{66}$ e em uma família italiana, desenvolve-se a forma clássica de DCJ. Como a penetrância dessa mutação é inconsistente, ela tem sido encontrada em alguns pacientes com DCJ esporádica ${ }^{62}$.

Inserções octapeptídicas, que ocorrem normalmente entre os códons 51 a 91, foram encontradas em famílias americanas, inglesas e japonesas, aparentemente não aparentadas entre si. Essas inserções levam a formas clínicas heterogêneas, mais comumente reconhecidas por ausência de sinais cerebelares precoces, mioclonias e anormalidades eletroencefalográficas ${ }^{64}$.

Basicamente, o diagnóstico de DCJ, como nas outras DP, é firmado pela presença de $\operatorname{PrP}^{\mathrm{Sc}}$, por genótipo mutante para a $\operatorname{PrP}$ e por achados imunoistoquímicos e eletroencefalográficos ${ }^{53}$. A possibilidade de DCJ deve sempre ser aventada em pacientes adultos com demência de evolução rápida, com LCR normal, e associada a mioclonias e complexos eletroencefalográficos periódicos ao $E G^{44}$, embora estes últimos possam estar ausentes nos estágios iniciais da doença. Também deve ser levada em conta em pacientes atáxicos e com déficits focais idiopáticos. Todas as doenças demenciais tratáveis devem ser especificamente avaliadas, antes que se faça o diagnóstico presuntivo. O EEG é procedimento diagnóstico crítico, e os métodos de imagem, como a tomografia computadorizada de crânio (TC) e a ressonância magnética (RNM), são pouco úteis. A eletroforese bidimensional da $\operatorname{PrP}^{\mathrm{Sc}}$ está sendo utilizada de modo crescente. O diagnóstico é estabelecido definitivamente por biopsia ou necropsia de tecido neural central, e confirmado por experimentos de transmissão para animais de laboratório ${ }^{37,54}$. O diagnóstico diferencial principal é feito com a doença de Alzheimer, diferenciando-se desta pela presença de mioclonias e EEG típico. Além deste, deve-se também pensar em depressão, encefalopatia pelo HIV, leucoencefalopatia multifocal progressiva e, mais raramente, tumores do SNC, encefalite límbica paraneoplásica e intoxicação por lítio.

\section{Doença de Gerstmann-Sträussler- Scheinker}

A doença de Gerstmann-Sträussler-Scheinker (GSS) é uma enfermidade neurodegenerativa rara, descrita inicialmente por Gerstmann em $1928^{35}$ e definida em 1936 por Gerstmann, Sträussler e Scheinker ${ }^{36}$. Possui um padrão de transmissibilidade autossômico dominante, sendo descritas seis formas clínicas relativamente distintas entre si, associadas a diferentes mutações genéticas (Tabela 1).
A GSS tem início insidioso, entre a terceira e a quinta décadas de vida. Contrariamente à DCJ, ataxia cerebelar de progressão lenta e demência grave, mas tardia, são as manifestações clínicas mais características, com sinais precoces de disartria, nistagmo e distúrbios visuais ${ }^{56}$. À medida que a doença avança, o paciente desenvolve sinais piramidais e extrapiramidais, como alterações no tônus muscular (espasticidade ou rigidez), diminuição dos reflexos profundos nos membros inferiores e sinal de Babinski. A demência torna-se proeminente, evoluindo para debilidade grave e morte dentro de dois a dez anos ${ }^{56}$.

A forma clínica determinada pela mutação no códon 105 do gene que codifica a PrP cursa com paraparesia espástica progredindo a quadriparesia e demência tardia, sem sinais cerebelares e mioclonias; já o quadro resultante da mutação no códon 117 revela-se por demência, parkinsonismo e sinais piramidais. A apresentação clínica das mutações nos códons 145, 198 e 217 são bastante semelhantes entre si, e caracterizados por demência lentamente progressiva, remetendo à doença de Alzheimer ${ }^{48}$. Porém, nas duas últimas ainda estão presentes sinais cerebelares $\mathrm{e}$ extrapiramidais.

A GSS deve ser aventada como diagnóstico diferencial em adultos com ataxia progressiva sem outras causas aparentes, especialmente quando esta afeta outros membros da família. Nos exames complementares, o exame do LCR e a tomografia podem ser normais, porém o EEG pode mostrar lentificação difusa. A RNM pode revelar atrofia cerebelar e sinal diminuído nos gânglios da base em imagens pesadas em $\mathrm{T} 2^{26}$. O diagnóstico de GSS pode ser confirmado pelo exame histopatologico do tecido cerebral, cuja apresentação típica o estabelece definitivamente.

\section{Insônia Familiar Fatal}

Recebe esta denominação pela predominância de distúrbios do sono no seu curso clínico. É uma DP hereditária autossômica dominante que, de modo semelhante à DCJ, é causada por uma mutação no códon 178 do gene que codifica a PrP. A expressão fenotípica desta mutação depende de polimorfismo normalmente silencioso no códon 129 da PrP; assim, sendo o paciente homozigótico para tal condição, haverá produção da $\mathrm{Pr}^{\mathrm{Sc}}$ especialmente no tálamo, definindo-se o diagnóstico de IFF. Quando essa mutação acontece em apenas um alelo, a distribuição da $\operatorname{PrP}^{\mathrm{Sc}}$ é mais difusa pelo encéfalo, e as manifestações clínicas decorrentes serão compatíveis com $\mathrm{DCJ}^{32}$. 
A IFF tem curso subagudo, iniciado geralmente na quarta ou quinta década de vida. Apesar de as manifestações clínicas serem geralmente monótonas e pouco variáveis entre os indivíduos afetados, existem duas variantes, de acordo com a duração do quadro clínico, que a princípio parecem ser determinadas geneticamente. Alguns indivíduos têm curso clínico rápido - entre seis e 13 meses de duração -, ao passo que existem pacientes cuja doença evolui mais demoradamente, em geral por dois a quatro anos.

A doença instala-se com insônia grave e intratável, melhor definida como dificuldade crescente em adormecer. Revelam-se também disautonomias causadas por hiperatividade simpática, como hipertensão, taquicardia, hiperidrose e hipertermia. Posteriormente, em poucas semanas ou meses após o surgimento da insônia, o paciente apresenta distúrbios motores, como disfagia, ataxia e mioclonias, além de distúrbios comportamentais e cognitivos, tais como déficit de atenção e memória, e inabilidade de ordenar eventos temporalmente. A IFF progride com a persistência dos sintomas, e com estado confusional ("dream-like state"). Se o indivíduo tem a forma de progressão rápida da doença, ele usualmente morre por falência cardiorrespiratória; nos casos em que a doença apresenta evolução mais lenta, a morte sobrevém, em geral, por complicações pulmonares ${ }^{33}$.

\section{Outras doenças}

Manueldis e Rorke descreveram uma criança de dois anos e meio com retardo de desenvolvimento, que faleceu de uma condição neurológica referida pelos autores como "doença de Alpers" 55 . A transmissibilidade desta doença foi comprovada por inoculação de tecido cerebral do paciente em hamsters. Este trabalho levanta a interessante possibilidade de que certas condições neurodegenerativas infantis possam ser causadas por mecanismos análogos àqueles envolvidos na DCJ.

Em 1986, uma epidemia de um mal previamente desconhecido foi detectada em rebanhos bovinos da Grã-Bretanha. Esta doença, denominada "encefalopatia espongiforme bovina" (EEB), tornou-se também conhecida pela alcunha de "doença da vaca louca", atualmente incluída entre as DP. Mais de 150.000 casos acometendo, principalmente, gado leiteiro foram descritos até o presente momento. Provavelmente, a EEB surgiu a partir da introdução na alimentação destes rebanhos de suplemento alimentar obtido de restos orgânicos de ovelhas - algumas delas com scrapie em fins da década de 70 . Desde 1988, esta prática foi banida do Reino Unido ${ }^{73}$. A doença da vaca louca caracteriza-se por alterações posturais e comportamentais (apreensão, mudança de temperamento), além de incoordenação motora ${ }^{20}$. Devido à epidemia de EEB e ao receio de que o consumo humano de derivados bovinos pudesse acarretar doença similar à DCJ, foi instituído em 1990, no Reino Unido, um sistema de vigilância epidemiológica com o objetivo específico de verificar alterações na ocorrência desta doença. Como resultado, em 1996 foram identificados dez novos casos de DCJ esporádica com características clínicas e neuropatológicas especiais, sendo portanto considerados como uma nova variante da DCJ $(\mathrm{vDCJ})^{74}$.

Clinicamente, a vDCJ caracteriza-se por acometer adultos jovens (início entre 15 e 42 anos), com sintomatologia psiquiátrica e cerebelar de evolução rápida. Os sintomas predominantemente psiquiátricos (e não demenciais) e atáxicos assemelham-se mais ao Kuru do que a casos clássicos de DCJ. Ao contrário da maioria dos casos de DCJ, a alteração anatomopatológica típica desta variante concentra-se nos gânglios da base e no tálamo. Além disso, placas de Kuru são amplamente distribuídas pelo encéfalo. Nesta variante, também não se observam os achados eletroencefalográficos típicos da DCJ ${ }^{74}$.

A descrição desta nova variante levantou à possibilidade de uma associação causal com a EEB. Ainda se discute se esta assertiva é verdadeira ou não. Evidência favorável a esta associação foi dada recentemente por autores ingleses, ao constatarem que as "cepas" isoladas de pacientes com vDCJ eram mais relacionadas às de animais com EEB do que as de pacientes com DCJ clássica ${ }^{21}$.

A possibilidade da aquisição de uma doença grave e fatal a partir do consumo de carne bovina levou praticamente ao colapso da exportação e consumo interno de carne vermelha oriunda do Reino Unido, e de sérios danos ao mercado importador de carne da União Européia ${ }^{3}$.

\section{PERSPECTIVAS TERAPÊUTICAS}

Atualmente não se conhece tratamento eficaz para as DP. Do mesmo modo a literatura não registra nenhum caso bem documentado de recuperação, quer espontânea, quer pós-tratamento. Apesar disso, uma vez que na atualidade já é possível o diagnóstico precoce e présintomático das DP hereditárias, torna-se imperativo o desenvolvimento de uma terapia específica. Tais doenças 
podem ser prevenidas através do uso de testes pré-natais de DNA. A despeito disso, a aparente penetrância incompleta de algumas das DP hereditárias torna temerário prever-se o futuro de um carreador assintomático.

Uma vez que a ablação do gene $\operatorname{PrP}$ em ratos transgênicos não parece ter qualquer efeito nocivo a esses animais, tornando-os, inclusive, resistentes à infeç̧ão ${ }^{15}$, existe a possibilidade do uso de oligonucleotídeos anti-sense ou de terapia de manipulação gênica no tratamento de doentes com DP. Outra possibilidade teórica seria a utilização de drogas que bloqueassem a conversão de $\operatorname{PrP}^{C}$ em $\operatorname{PrP}^{S c}$. Uma vez que o evento fundamental tanto na formação de $\operatorname{Pr} P^{S c}$ quanto na sua propagação parece ser a abertura da estrutura protéica em alfa-hélices da $\operatorname{PrP}$ e a sua subsequiente transformação em lâminas beta, drogas que impeçam esta transformação estrutural poderiam ser utilizadas no tratamento de tais doentes. Tais drogas não estão disponíveis no momento.

Com base nos conhecimentos acerca dos mecanismos etiopatogênicos envolvidos nas DP, não há base consistente para a utilização de vacinas ou qualquer forma de imunização passiva na profilaxia dessas doenças.

\section{SUMMARY}

Prion (auto-replicative proteins lacking nucleic acids) diseases are a group of chronic, progressive and fatal diseases, caused by, an unconventional transmissible agent. These conditions, unlike others, can be sporadic, transmlssible and Inherited. The major human diseases caused by Prions are Kuru, Creutzfeldi-Jakob disease and its variants, Gerstmann-StrăusslerScheinker disease, and fatal familial insomnia. In this paper we review the most recent ethiopathogenic, anatomopathologic, clinical and therapeutic aspects of these important neurodegenerative diseases.

\section{KEYWORDS}

Spongiform encephalopathies, Creutzfeldt-Jakob disease, prions, amyloidosis, dementias.

\section{Referências}

1. Askanas, V; Bilak, M; Engel, WK; Leclerc, A; Tomé, F. Prion protein is strongly immunolocalized at the postsynaptic domain of human normal neuromuscular junctions. Neurosci Lett, 159: 111-114, 1993.

2. Au, WJ; Gabor, AJ; Vigayan, $\mathrm{N}$; et al. Periodic lateralizing epileptiform complexes in Creutzfeldt-Jakob disease. Neurology, 30: 611-617, 1980.

3. Baker, HF; Ridley, RM. What went wrong in BSE? From prion disease to public disaster. Brain Res Bull, 40:237-244, 1996.

4. Bernoulli, C; Siegfried, J; Baumgartner, G; et al. Danger of accidental person-to-person transmission of CreutzfeldtJakod disease by surgery. Lancet, 1: 478-479, 1977.

5. Bockman, JM; Kingsbury; DT; McKinley, MP; et al. CreutzfeldtJakob disease prion proteins in human brains. $N$ Engl J Med, 312: 73-78, 1985.
6. Bolton, DC; Mckinley, MP; Prusiner, SB. Identification of a protein that purifies with the scrapie prion. Science, 218: 13091311, 1982.

7. Borchelt, DR; Koliatsis, VE; Guarnieri, M; Pardo, CA; Sisodia, SS; Price, DL. Rapid anterograde axonal transport of the cellular prion glycoprotein in the peripheral and central nervous systems. J Biol Chem, 269: 14711-14714, 1994.

8. Borchelt, DA; Scott, M; Taraboulos, A; Stahl, N; Prusiner, SB. Scrapie and cellular prion proteins differ in their kinetics of synthesis and topology in cultured cels. J Cell Biol, 110: 743$752,1990$.

9. Borchelt, DR; Taraboulos, A; Prusiner, SB. Evidence for synthesis of scrapie prion proteins in the endocytic pathway. J Biol Chem, 267: 16188-16199, 1992.

10. Brown, P; Cathala, F; Raubertas, RF; et al. The epidemiology of Creutzfeldt-Jakob disease: Conclusion of a 15-year investigation in France and review of the world literature. Neurology, 37: 895-904, 1987.

11. Brown, P; Gálvez, S; Goldfarb, LG; et al. Familial CreutzfeldtJakod disease in Chile is associated with the codon $200^{\text {aen }}$ mutation of the chromossome 20 amyloid precursor gene. $\mathrm{J}$ Neurol Sci, 112: 65-67, 1992.

12. Brown, P; Goldfarb, LG; Gajdusek, DC. The new biology of spongiform encephalopathies: infectious amyloidosis with a new twist. Lancet, 337: 1019-1022, 1991.

13. Brown, P; Preece, MA; Will, RG. "Friendly-fire" in medicine: hormones, homografts, and Creutzfeldt-Jakob disease. Lancet, 340: 24-27, 1992.

14. Büeler, $H_{;}$Aguzzi, A; Sailer, $A$; et al. Mice devoid of PrP are resistant to scrapie. Cell, 73: 1339-1347, 1993.

15. Büeler, H; Fischer, $M$; Lang, Y. Normal development and behaviour of mice lacking the neuronal cell-surface PrP protein. Nature, 356: 577-582, 1992.

16. Chapman, J; Brown, P; Goldfarb, LG; Arlazoroff, A; Gajdusek, DC; Korcezyn, AD. Clinical heterogeneity and unusual presentations of Creutzfeldt-Jakob disease in Jewish patients with the PRNP codon 200 mutation. J Neurol Neurosurg Psych, 56: 1109-1112, 1993.

17. Chesebro, B; Fields, BN. Transmissible spongiform encephalopathies: a brief introduction. In: Fields Virology. Fields, BN; Knipe, DM; Howley, PM; et al. (eds). LippincottPaven: Philadelphia, 1996, pp. 2845-2849.

18. Chiofalo, N; Fuentes, A; Galvez, S. Serial EEG findings in 27 cases of Creutzfeldt-Jakob disease. Arch Neurol, 37:143-145, 1980.

19. Cohen, FE; Pan, K-M; Huang, Z; Baldwin, M; Fletterick, RJ; Prusiner, SB. Structural clues to prion replication. Science, 264: 530.531, 1994.

20. Collee, JG; Bradley, R. BSE: a decade on - part I. Lancet, 349: 636-641, 1997.

21. Collinge, J; Sidle, KC; Miads, J; Ironside, J; Hill, AF. Molecular analysis of prion strain variation and the aethiology of "new variant" CJD. Nature, 383: 685-690, 1996.

22. Collinge, J; Whittington, MA; Slide, KC. Prion protein is necessary for normal synaptic function. Nature, 370: 295297.

23. Creutzfeldt, HG. Über eine eigenartige herdfōrmige Erkrankung des Zentralnervensystems. Neurol Psychiat, 57: 1-18, 1920.

24. Crullé, J; Chelle, PL. Pathologie animal - la maladie dite tremblant du mouton est-elle inoculable. C R Acad Sci (Paris), 203: 1552-1554, 1936.

25. Duffy, P; Wolf, J; Collins, G; DeVoe, AG; Steeten, B; Cowen, D. Possible person-to-person transmission of CreutzfeldtJakob disease. N Engl J Med, 299: 692-693, 1974.

26. Farlow, MR; Yee, RD; Dlouhy, SR; et al. Gerstmann-StrāusslerScheinker disease. I. Extending the clinical spectrum. Neurology, 39:1446-1452, 1989. 
27. Gajdusek,DC; Zigas, V. Degenerative disease of the central nervous system in New Guinea: The endemic occurrence of "kuru" on the native populations. N Engl J Med, 257: 974978, 1957.

28. Gajdusek, D.C. Unconventional viruses and the origin and disappearance of Kuru. Science, 197: 943-960, 1977.

29. Gajdusek, DC. Infectious amyloids: subacute spongiform encephalopathies as transmissible cerebral amyloidoses. In: Fields Virology. Fields, BN; Knipe, DM; Howley, PM; et al. (eds.). Lippincott-Raven: Philadelphia, pp. 2851-2900.

30. Gajdusek, DC; Gibbs, CJ Jr; Alpers, M. Experimental transmission of a kuru-like syndrome in chimpanzes. Nature, 209: 794-796, 1966.

31. Gajdusek, DC; Zigas, V. Kuru: Clinical, pathological and epidemiological study of acute progressive degenerative disease of the central nervous system among natives of the Eastern Highlands of New Guinea. Am J Med, 26: 442.469, 1959.

32. Gambetti, P. Fatal familial insomnia and familial CreutzfeldtJakob disease: a tale of two diseases with the same genetic mutation. Curr Top Microbiol Immunol, 207: 19-25, 1996.

33. Gambetti, P. Pathology of human prion diseases. In: Corczyn, AD; Prusiner, ES; eds: Human Prion diseases, syllabus 329, Boston: American Academy of Neurology, 43-63, 1997.

34. Gambetti, P; Parchi, P; Petersen, RP; Chen, SG; Lugaresi, E. Fatal familial insomnia and familial Creutzfeldt-Jakob disease: clinical, pathological and molecular features. Brain Pathol, 5: 43-51, 1995.

35. Gerstmann, J. Über ein noch night beschriebenes Reflexphanomen bei einer Erkrankung des zerebellaren Systems. Wien Med Wochenschr, 78: 906, 1928.

36. Gerstmann, J; Străussler, E, Scheinker, 1. Über eine eigenartige hereditar-familiare Erkrankung des Zentralnervensystems. Zugleich ein Beitrag zur Frage des vorzeitigen lokalen Alterns. Z Neurol, 154: 736, 1936.

37. Gibbs, CJ Jr; Gajdusek, DC; Asher, DM; et al. CreutzfeldtJakob disease (spongiform encephalopathy): Transmission to the chimpanzee. Science, 161: $388,1968$.

38. Glasse, R: Cannibalism in the kuru region of New Guinea. Trans NY Acad Sci, 29: 748, 1967.

39. Goldfarb, L; Brown, P; Gajdusek, DC. Multiple mutations in Creutzfeldt-Jakob disease and Gerstmann-SträusslerScheinker syndrome. Brain Res Rev, 16: 98-99, 1991.

40. Goldfarb, LG; Brown, P; Mitrová, E; et al. Creutzfeldt-Jakob disease associated with the PRNP codon $200^{\text {lys }}$ mutation: an analysis of 45 families. Eur J Epidemiol, 7: 477-486, 1991.

41. Griffith, JS. Self-replication and scrapie. Nature, 215: 10431044, 1967

42. Hadlow, WJ. Scrapie and kuru. Lancet, 2: 289, 1959.

43. Haltia, M; Kovanen, J; Goldfarb, LG; Brown, P; Gajdusek, DC. Familial Creutzfeldt-Jakob disease in Finland: epidemiological, clinical, pathological, and molecular genetic studies. Eur J Epidemiol, 7: 494-500, 1991.

44. Hornabrook, RW; Wagner, F. Creutzfeldt-Jakob disease. Papua New Guinea Med J, 18: 226-228, 1975.

45. Hsich, G; Kenney, K; Gibbs, CL; Lee, KH; Harrington, MG. The 14-3-3 brain protein in cerebrospinal fluid as a marker for transmissible spongiform encephalopathies. N Engl J Med, 335: 924-930, 1996.

46. Jakob, A. Über eine der multiplen sklerose klinisch nahestehenda Erkrankung des Zentralnervensystems (Spastische Pseudosklerose) mit bemerkenswertem anatomischen Befunde. Med Klin, 13: 372-376, 1921.

47. Jendroska, K; Heinzel, FP; Torchia, M. Proteinase-resistant prion protein accumulation in Syrian hamster brain correlates with regional pathology and scrapie infectivity. Neurology, 41: 1482-1490, 1991.

48. Kitamoto, T; Doh-ura, K; Muramota, T; Miyazono, M; Tateishi, $J$. An amber mutation of prion protein in Gerstmann-
Sträussler syndrome with mutant PrP plaques. Biochem Biophys Res Commun, 192: 525-31, 1993.

49. Kitamoto, T; Tateishi, J; Sato, Y. Immunohistochemical verification of senile and kuru plaques in Creutzfeldi-Jakob disease and the allied disease. Ann Neurol, 24: 537-542, 1988.

50. Klatzo ,I; Gajdusek, DC; Zigas, V. Pathology of kuru. Lab Invest, 8: 799-847, 1959.

51. Kocisko, DA; Come, JH; Priola, AS; et al. Cell-free formation of protease-resistant prion protein. Nature, 370: 471-474, 1994.

52. Kretzschmar, HÁ; Prusiner, SB; Stowring, LE; DeArmond, SJ. Scrapie prion proteins are synthesized in neurons. Am J Pathol, 122: 1-5, 1986.

53. Lantos, PL; McGill, IS; Janota, I; et al. Prion protein immunocytochemistry helps to stablish the thrue incidence of prion diseases. Neurosci Lett, 147: 67-71, 1992.

54. Manuelidis, EE. Transmission of Creutzfeldt-Jakob disease from man to the guinea pig. Science, 190: 571, 1975.

55. Manuelidis, EE; Rorke, LB. Transmission of Alpers' disease (chronic progressive encephalopathy) produces experimental Creutzfeldt-Jakob disease in hamsters. Neurology 39: 615621,1989

56. Masters, CL; Gajdusek, DC; Gibbs, CJ Jr. Creutzfeldt-Jakob disease virus isolations from the Gerstmann-Sträussler syndrome: With an analysis of the various forms of amyloid plaque deposition in the virus-induced spongiform encephalopathy. Brain, 104: 559-588, 1981.

57. Masters, CL; Richardson, EP Jr. Subacute spongiform encephalopathy (Creutzfeldt-Jakob disease). The nature and progression of spongiform change. Brain, 101: 333-344, 1978.

58. Mobley, WC; Neve, RL; Prusiner, SB; McKinley, MP. Nerve growth factor increases mRNA levels for the prion protein and the beta-amyloid protein precursor in developing hamster brain. Proc Natl Acad Sci (USA), 85: 9811-9815, 1988.

59. Nieto, $A ;$ Goldfab, LG; Brown, $P$; et al. Mutation in codon 18 of amyloid precursor gens occurs in Creutzfeldt-Jakob disease of diverse ethnic origins. Lancet, 337:622-623, 1991.

60. Oesch, B; Westaway, D; Walchli, M; et al. A cellular gene encodes scrapie PrP 27-30. Cell 40: 735-746, 1985.

61. Pan, KM; Baldwin, M; Nguyen, J. Conversion of alpha-helices into beta-sheets features in the formation of the scrapie prion proteins. Proc Natl Acad Sci (USA), 90: 10962-10966, 1993.

62. Pocchiari, $M$; Salvatore, $M$; Cutruzzolá, $F$; et al. A new point mutation of the prion protein gene in Creutzfeldt-Jakob disease. Ann Neur, 35: 802-807, 1993.

63. Prusiner, SB. Novel proteinaceous infectious particles cause scrapie. Science, 216: 136-144, 1982.

64. Prusiner, SB. Prions. In: Fields Virology. Fields, BN; Knipe, DM; Howley, PM; et al. (eds.). Lippincott-Raven: Philadelphia, pp. 2901-2950, 1996.

65. Prusiner, SB; Fuzi, M; Scott, M; et al. Immunologic and molecular biological studies of prion proteins in bovine spongiform encephalopathy. J Infect Dis, 167: 602-613, 1993.

66. Ripoll, $L_{;}$Lanplanche, J-L; Salzmann, $M$; et al. A new point mutation in the prion proteingene at codon 210 in CreutzfeldtJakob disease. Neurology, 43: 1934-1938, 1993.

67. Sparkes, RS; Simon, M; Cohn, VH. Assignment of the human and mouse prion protein genes to homologous chromosomes. Proc Natl Acad Sci (USA) 83: 7358-7362, 1986.

68. Stahl, N; Baldwin, MA; Teplow, DB. Structural analysis of the scrapie prion protein using mass spectrometry and amino acid sequencing. Biochemistry, 32: 1991-2002, 1993.

69. Stahl, N; Borchelt, DR; Hsiao, K; Prusiner, SB. Scrapie prion protein contains a phosphatidylinositol glycolipid. Cell, 51 : 229-240, 1987.

70. Stockman, S. An obscure disease of sheep. J Comp Pathol, 26: 317-327, 1913. 
71. Taraboulos, A; Scott, M; Semenov, A; Avrahami, D; Laszlo, $\mathrm{L}$; Prusiner, SB. Cholesterol depletion and modification of Cterminal targeting sequence of the prion protein inhibit formation of the scrapie isoform. J Cell Biol, 129: 121-132, 1995.

72. Thadani, V; Penar, PL; Partington, J; et al. Creutzfeldt-Jakob disease probably acquired from a cadaveric dura mater graft. J Neurosurg, 69: 766-769, 1988.

73. Wilesmith, J;Wells, GAH. Bovine spongiform encephalopathy. Curr Top Microbiol Immunol, 172: 21-38, 1991.
74. Will, RG; Ironside, JW; Zeidler, M; et al. A new variant of Creutzfeldt-Jakob disease in the UK. Lancet, 347: 921-925, 1996.

\section{Endereço para correspondência:}

Abelardo de Queiroz-Campos Araújo

Hospital Universitário Clementino Fraga Fitho - UFRJ

Av. Brigadeiro Trompowski, $s / n^{2}$

Rio de Janeiro (RJ)

e-mail: neuron centroin.com.br

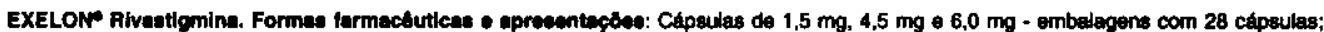
cápsulas de $3,0 \mathrm{mg}$ - embalagens com 28 e 56 cápsules. Indleacóa: Tratamento de pacientes com demôncia leve a moderedamente grave do tlpo Alzheimer (provavel Doenca de Alzheimer) ou Doenca de Azhelmer. Contre-indicacbes: Pacientes com conhecida hlpersensilbilldede a rivastlgmina, a outros derivados do carbamato au a qualquer componente da fórmula. Advertíncias e preciuçóes: Cuidado em paclentes com doença do no sinusal ou com arritmias cardiacas graves. Precauç50 em pacientes precispostos a estados ulcerosos, em paclentes portadores ou com hisłórico de doença resplratórla e precauçá nos casos de obstnuça urinária e convulsðes. EXELON" deve ser utillzedo em mulheres grávidas apenas se o beneficlo potencial for superior ao possivel risco ao feto. Pacientes que utilizam EXELON nato devem amamentar. A

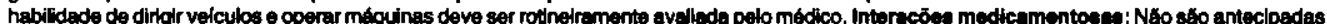
interaçठes farmacocinéticas com outras drogas metabolizadas por isoenzlmas do citocromo P450. Náo foram observadas interaçöes farmacochnétcas com digoxina, warfarina, diazepam ou fluoxetina em estudos em voluntários sadios. Em pacientes, a adminlstraç6 concomintante com antiécidos, antiemótcos, antidlabétcos, anti-hipertens/vos de aça central, beta-bloqueadores, bloqueadores do canal de cálcio, drogas inotróopicas, antianginosos, antlinflamatórios năo esteroldais, estrógenos, analgésicos, benzodiazepínicos $\theta$ anti-histaminicos nelo fol assoctada a alteraços farmacocinéticas. Nê deve ser adminlstrado concomltantemente com outras drogas collinomiméticas e pode interferir na attvidade de medlcacoses anticolinérgices. EXELONo pode potencializar os efeitos de relaxantes musculares do tpo succllcoline durante a anesteala. Reaçóes adverans: Incidencia lgual ou superior a $5 \%$, independente de apresentar uma relaça de causa com EXELONo: trauma acidental,

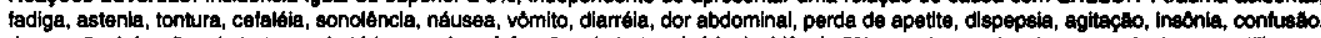
depressáo, infecçbes do trato respiratório superior e infecçoes do trato urinário. Incidéncla $2 \%$ superior ao placebo em pacientes que utilizaram EXELONo: aumento da sudorese, mal-estar, perda de peso e tremor. Pacientes do sexo ferminino se mostraram mals suscetivets a náusea. vómito, perda de apetite e perda de peso. Posologia: Deve ser administrado duas vezes ao dia, corn as refeiçes de manha e de noite. Dose Inicial: 1.5 mg duas vezes ao dia. Aiuste de dose: Se a dose Inicial for bem tolerada apces pelo menos 2 semanas de tratamento, pode ser aumentade para $3 \mathrm{mg}$ duas vezes ao dla. Aumentos subseqüentes para $4,5 \mathrm{mg}$ e entho para $6 \mathrm{mg}$ duas vezes ao dia tamberm devem estar beseadas em boa folerabilidade a dose corrente $\theta$ apds um minimo de 2 semanas de tratamento nequele nivel de dose. Se forem observados efertos adversos ou diminulçto de peso durante o tratamento, omitir uma ou mals coses. Se os efeitos adversos persistirem, a dose diárla deve ser reduzida a dose anterior que apresentou boa folerabilidede. Does de manutencto: 1.5 a $6 \mathrm{mg}$ duas vezes ao dia: para atingir o beneliclo terapêtutico máximo, os pacientes devern ser mantidos na dose bern tolerada mais elevada. Dose máxima diária reciomendada 6 mg duas vezes a dia. Uso em pecientes com insufficiéncia nenel ou hepética: NGo é necessadio realizar ajuste de dose em pecientes com insuficiêncie renel ou hepática. Superdosagem: Nos casos de superdosagem assintomática, nenhuma dose de EXELONo deve ser adminlstrada pelas próxímas 24 horas. Nos casos de superdosagem acompanhada por vómito e nálusea grave, o uso de antieméticos deve ser considerado. Tratamento sintomátlco para cutros eventos adversos deve ser realizado se necessário. Em casos de superdosagem grave, a atropina pode ser utillzada. Recomendase uma dose inklal i.v. de $0,03 \mathrm{mg} / \mathrm{kg}$ de sulfato de atropina, com doses subseqDentes baseadas na resposta clínica. Náo é recomendado o uso da escopolemina como antidoto.

Nota: Informapdes completas para prescriç. disponiveis mediante solicitaçfo. 